\title{
A comparison of teenage views on journalism as a career in Australia and New Zealand
}

\section{ABSIRACII}

Australian and New Zealand journalism programmes report a disproportionate number of female students and the industry in both countries is becoming increasingly feminised. Densem (2006) explored the reasons for the popularity of journalism as a career among young New Zealand women and the relative lack of appeal for young men. This article reports upon preliminary results from an Australian study covering some common ground and offers some comparisons and contrasts with the New Zealand findings. This article uses the high school student responses from a larger study as the basis of comparison with similar data in the Densem (2006) study. Key similarities are that young respondents in both countries did not see journalism as a 'blokey' career; many showed ignorance about journalism salaries; and they perceived both male and female journalists as intelligent and serious. Students in both countries perceived good looks as a more important quality for female journalists than males. There were, however, marked differences in the responses of high school males in Australia to the perceptions of the qualities of female journalists. Rather than the intelligence, credibility and seriousness they assigned to male journalists (and their New Zealand male counterparts also assigned to female journalists), the young Australian males ranked good looks, pushiness and nosiness as the chief qualities assigned to female journalists, a disturbing finding worthy of more investigation.

Keywords: cadetships, credibility, gender, journalism education, role models

\section{MARK PEARSON}

Bond University 
$\mathrm{F}$ IOR at least the past 20 years females have outnumbered males among the ranks of journalism students and entry-level recruits. Patching (1997,pp. 103-104) found that females outnumbered males by between 2-1 and 4-1 at Australia's tertiary journalism courses. Pearson studied newspaper cadetship applicants in 1988 and found a 2:1 female: male ratio in respondents to a survey of that cohort (Pearson, 1988). Densem (2006) reported the ratio as high as 7:1 in New Zealand courses. Becker et. al. (2008, p. 206) noted a slight drop in the number of female students in US journalism and mass communication courses to about two thirds of the cohort in 2007.

Several researchers have studied the motivations of students choosing a career in journalism. They have identified factors such as their perceptions of the career and their own interests and skill-bases. Role models such as careers advisers and teachers were found to be significant influences. Splichal and Sparks (1994, p. 138) found that around 58 percent sought advice in choosing their career. Fitzsimmons and Bilboe (1999) found that 83 percent of 81 surveyed attributed their journalism career choice to the advice of a teacher, while about 15 percent traced it back to the advice of a primary school teacher.

Henningham's 1996 research backed up Splichal and Sparks' Australian finding that students most often chose journalism because of their ability to write. Pearson's 1988 survey found applicants excelled in English and enjoyed the subject. They wanted a career centred on writing (Pearson, 1988, p. 126). This interest in writing was also a key factor identified by Fisher (1978) and Splichal and Sparks (1994).

Other motivating factors identified have been an interest in current events and the public service ethos of journalism (Hanna \& Sanders, 2007). Journalism's credibility as an occupation has been proposed as both a reason for entry (Endres \& Warden, 1990) and (with its lack of credibility in the negative) as an explanation as to why more females and fewer males were choosing it as a career (Hollings et al, 2007). Other negative views seen as reasons for students not adopting it included its being 'boring' (Frith \& Meech, 2007), time consuming, and stressful (Endres \& Weardon, 1990).

Other studies have focussed almost exclusively on the views of young people who have already nominated journalism as their career choice as either tertiary journalism students (Alysen \& Oakham, 1996; Patching, 1997) or newspaper cadetship applicants (Pearson, 1988). 
The Australian Census conducted in 2006 showed for the first time that more women than men nominated journalism as their occupation. In 2001, the Australian Bureau of Statistics reported marginally more men (8296) than women (8220) in the category 'Journalists and Related Professionals', totalling 16,516 (ABS, 2001: Occupation by SEX (a) - Persons (CC55)). By 2006, this had changed significantly to 8941 men and 9763 women, totalling 18,704 (ABS, 2006: Cat. No. 2068.0 - 2006, based on the 1996 Australian Standard Classification of Occupations (ASCO)). (See Table 1). The only major media sub-category still showing a majority of males in 2006 was print journalism, with 3199 males (50.7 percent) to 3106 females (49.3 percent), totalling 6305 (ABS, 2006: Cat. No. 2068.0, Alternative View (b): Culture and Leisure Occupations).

Table 1: Journalists and related professionals by gender

\begin{tabular}{|c|c|c|c|}
\hline Year & Male & Female & Total \\
\hline 2001 & $8296(50.2 \%)$ & $8220(49.8 \%)$ & 16516 \\
\hline 2006 & $8941(48 \%)$ & $9763(52 \%)$ & 18704 \\
\hline
\end{tabular}

Source: ABS

This historic shift, combined with reports of substantially higher numbers of females in tertiary journalism programmes nationally, prompts important research questions about young females' and young males' motivations for selecting a career in journalism and the influences upon their decisions.

This article reports on a survey of 444 Australian high school students which was undertaken as part of wider research into the 'feminisation of the media' in Australia. Other elements of the study included surveys of high school careers advisers about their guidance on the matter, and in-depth interviews with journalism 'elites' about their perceptions of the potential implications of the increasing numbers of women working in journalism in Australia. Those results are the subject of other research papers and articles.

Day (2004) suggested the higher number of females working in journalism might be a self-perpetuating phenomenon, operating as an incentive to women to join an occupation seen as suitable for women. Several scholars have identified and researched the notion of the 'feminisation of the media', exploring gender issues in the newsroom and also the more 'feminised' content of media products, including Margareta Merlin-Higgins (2004), Djerf-Pierre (2007) and Robinson (2008). These researchers and others have also explored the 'glass 
ceiling' phenomenon confronting women in newsrooms internationally, whose numbers have been increasing but notably not broadly across senior editorial positions. Bettina Peters' 2001 study for the International Federation of Journalists found women comprised more than one third of journalists worldwide but occupied only 0.6 percent of positions as editors, heads of departments or media owners (Peters, 2001, p. 4). More recently, the notion of the culture and practices of the 'gendered newsroom' in Australia has been explored in an empirical study by Louise North (2009).

This article concentrates on a relatively narrow comparison of the results of our survey of 444 16-18-year-old Australian high school students (182 males and 262 females) with a survey of 160 New Zealand high school students (73 males and 87 females) conducted by Yvonne Densem (2006). Densem (2006) explored the reasons for the popularity of journalism as a career among young New Zealand women and the relative lack of appeal for young men. Her study also featured several research methods including focus groups, short interviews, in-depth interviews and questionnaires distributed to both secondary school students and tertiary journalism students (Densem, 2006, p. 42). For the purposes of this article, we are only using the results of her survey of the sample of 160 secondary school students, for which she has kindly provided the results upon which her article was based.

The reason we are exploring the views of the broader population of high school students in both countries is that previous studies have focussed almost exclusively on the views of young people who have already nominated journalism as their career choice as either tertiary journalism students (Alysen \& Oakham, 1996; Patching, 1997) or newspaper cadetship applicants (Pearson, 1988). This is important because it is more likely to offer insights into why young people, particularly young males, might not be selecting journalism as a career in the two countries. Further, the cross-national comparison might provide insights into whether students are selecting journalism, or not selecting journalism, for similar reasons in the two countries.

\section{Method}

Yvonne Densem (2006) described her broader methodology in her Pacific Journalism Review article. As stated above, for this project our research team was most interested in the responses of the 160 Christchurch secondary school students she had interviewed, whose responses did not feature strongly in that article, so she kindly provided tables with statistical 
breakdowns of their responses to her various survey questions. Only some of those questions were directly comparable with those our team asked 444 secondary school students (male 182, female 262) from government and private schools in south-east Queensland, NSW and South Australia in mid-2008.

\section{Limitations}

The results should be viewed with some caution for a range of reasons. Firstly, the Densem sample was only drawn from Christchurch, so a broader New Zealand study might generate different results. Secondly, the Densem study used categorical data which tends to restrict the participants' responses more than a combination of categorical and numerical data used in the Australian survey. Thirdly, for the questions asking students to assess the qualities of female and male journalists, the Christchurch study used a 'tick all that apply' approach, whereas our survey used a Likert scale format that allows for a selection among possible responses. Finally, levels of significance were not available for the New Zealand results. In short, it is recommended that a future researcher, perhaps a postgraduate student, embarks upon a more comprehensive cross-national comparison where the instrument is identical for both samples.

\section{Results and discussion}

The questions with enough commonality for a cross-country comparison can be grouped into four categories: students' news diets; perceptions of journalism as a career; perceptions of male journalists; and perceptions of female journalists.

Students' news diets

High school students in both countries were asked the identical question 'How often do you catch up on the news?' Of the Christchurch students, 64 percent (70 percent male, 59 percent female) claimed to access the news on a daily basis, whereas only 56 percent of Australian students (55 percent male, 57 percent female) nominated daily access to news. This is interesting, and certainly worthy of further study exploring high school students' notions of 'news', particularly given recent reports of the rising popularity of celebrity news and gossip among this demographic group (Economist, 2005). More significant were differences between the types of media accessed by the 
students in the two countries. The New Zealand students accessed more of their news from traditional media while in Australia there were significantly more using the Internet as a news source. This could well be explained by the three year difference in the data collection periods (2005-2008). Television led the field in both groups ( 59 percent NZ, 49 percent Australia), followed by radio in New Zealand (30 percent) and multiple sources in Australia (29 percent). Next was newspapers in New Zealand with 18 percent and the internet a long last at only 3 percent. This contrasted markedly with Australia, where the internet took third place with 11.5 percent followed by radio and newspapers at exactly 3.6 percent each. Gender differences in each country were noteworthy, with males being stronger television viewers in both countries. Males were slightly more likely to source news from the internet and newspapers than females in New Zealand, while in Australia teenage girls were significantly higher users of all media apart from television as a news source and were also more likely than boys to access news from multiple sources.

\section{Perceptions of journalism as a career}

The survey questions gauging the teenagers' views on journalism as a career differed somewhat in the two studies, so the results and discussion here are limited to the six factors shared by the questionnaires. The key question in the New Zealand study offered four terms - interesting, serious, difficult and fun-and asked students 'Which of the following best describes the career of journalism?'. In other words, it forced respondents to choose between the four. The Australian study gave respondents a five-point Likert scale response option to 15 terms, including three of those four or their antonyms (ie, boring rather than interesting) and including 'blokey' as one of the terms listed. For various reasons it did not ask whether students perceived the career as 'serious'. The New Zealand survey devoted a separate question on whether students perceived journalism as a 'blokey' career. (This, of course, prompts questions about the students' understanding of that term and its suitability given concerns about 'blokeyness' could be perceived as a newsroom issue they had not yet experienced.) Both studies asked separate questions on whether journalism was 'well paid' and 'well respected' as a career. These were the common elements worthy of comparison.

The different measurement systems rule out the assignation of numbers to the three common terms put to the students, however a direct comparison of 
Table 2: High school perceptions of journalism as a career

\begin{tabular}{|c|c|c|c|}
\hline & Interesting & Difficult & Fun \\
\hline New Zealand & 1 & 2 & 3 \\
\hline Australia & 2 & 1 & 3 \\
\hline
\end{tabular}

High school students' relative perceptions of journalism as a carrer in Australia and new Zealand.

their priorities to students is possible, as detailed in Table 2.

Without reading too much into this relatively complicated comparison, the most outstanding indication is that teenagers in neither country perceived journalism as a fun career, but were more inclined to see it as interesting or difficult, with those factors changing in priority across the two countries.

Both studies asked whether journalism was a 'blokey' career and, with the Australian Likert scale answers forced into a three-way response for these results, a direct comparison is possible, as detailed in Table 3.

\section{Table 3: High school perceptions of 'blokeyness' of journalism}

\begin{tabular}{|l|c|c|c|c|c|c|}
\hline 'Blokey' & \multicolumn{2}{|c|}{ New Zealand $(\mathrm{n}=160)$} & \multicolumn{3}{c|}{ Australia $(\mathrm{n}=444)$} \\
\hline & All & $\begin{array}{c}\text { Male } \\
(\mathrm{n}=73)\end{array}$ & $\begin{array}{c}\text { Female } \\
(\mathrm{n}=87)\end{array}$ & All & $\begin{array}{c}\text { Male } \\
(\mathrm{n}=182)\end{array}$ & $\begin{array}{c}\text { Female } \\
(\mathrm{n}=262)\end{array}$ \\
\hline Yes & $6 \%$ & $11 \%$ & $2 \%$ & $7 \%$ & $8 \%$ & $6 \%$ \\
\hline No & $78 \%$ & $70 \%$ & $85 \%$ & $66 \%$ & $59 \%$ & $71 \%$ \\
\hline Unsure & $16 \%$ & $19 \%$ & $13 \%$ & $27 \%$ & $32 \%$ & $23 \%$ \\
\hline
\end{tabular}

New Zealand and Australian high scholl students' perceptionsof the 'blokeyness' of journalism by nation and gender.

Again, there are strong similarities in the responses of high school students in both countries on the "blokeyness" of journalism as a career, with the overwhelming majority of males and females in both countries rejecting this descriptor. In both countries, it is the females who reject it most strongly $(\mathrm{NZ}=85$ percent; Australia $=71$ percent $)$, supporting the view that journalism has become a highly acceptable career for women. The evidence would not allow us to go far enough to state that it has become so feminised that this has a negative impact upon young men, although other parts of our Australian study have been exploring this aspect further with careers advisers and journalism elites.

Students in both countries were relatively ignorant of the journalists' remuneration, although fewer Australian students admitted not knowing 
whether journalists were well paid. In New Zealand, 63 percent of the teenagers stated they did not know if journalists were well paid (56 percent of males and 68 percent of females), while in Australia only 42 percent of the total sample admitted this ignorance ( 40 percent male and 44 percent female). This could well reflect a general naivety among high school students about relative salaries of different occupations, although it is noteworthy at least that the Australian students are admitting such ignorance.

There was a different impression of the perceived respect of journalism as a career across the two national groups. In Christchurch, 61 percent of all students surveyed agreed that journalism was a 'well respected career' (58 percent of males, 63 percent of females). However, in Australia only 42 percent overall nominated it as a well respected career (just 29 percent of males and 52 percent of females). Interestingly, 42 percent of the Australian students were neutral on the issue, indicating they were unsure of journalism's level of respect. The substantially lower level of respect for journalism among young Australian men (to a lesser extent in New Zealand) might provide the first major clue as to why the career appears to be less popular for the male gender. Perhaps young men are choosing their careers conscious of the level of respect the community assigns to them. Also interesting is the lower respect level for the career among the Australian sample. Might this be indicative of a stronger critical element in the media studies strands of the high school curriculum? The Australian study of careers advisers' and elite journalists' views might well shed light on this aspect.

\section{Perceptions of male journalists}

Both surveys canvassed the students' perceptions of both male and female journalists in a bid to ascertain any gender differences in these perceptions. Perhaps their views of journalistic role models shaped their own decisions on whether to enter this career. Again, some of the factors put to the New Zealand students were not used in the Australian study, and vice-versa, and the Australian Likert scale responses have been forced into a prioritised selection like the New Zealand study to enable a comparison. For both genders, we were left with a 'league table' of eight qualities showing the order of priorities the high school students assigned to the suggested characteristics of male and female journalists. Table 4 gives the adjusted table of characteristics assigned to male journalists, in the order in which the students deemed them appropriate. 
Table 4: Rankings of selected qualities of male journalists

\begin{tabular}{|l|c|c|c|c|c|c|}
\hline $\begin{array}{l}\text { Ranking of } \\
\text { qualities of male } \\
\text { journalists }\end{array}$ & \multicolumn{4}{|l|}{ New Zealand (n=160 students) } & \multicolumn{3}{|c|}{ Australia (n=444 students) } \\
\hline & All & $\begin{array}{c}\text { Male } \\
(\mathrm{n}=73)\end{array}$ & $\begin{array}{c}\text { Female } \\
(\mathrm{n}=87)\end{array}$ & All & $\begin{array}{c}\text { Male } \\
(\mathrm{n}=182)\end{array}$ & $\begin{array}{c}\text { Female } \\
(\mathrm{n}=262)\end{array}$ \\
\hline Intelligent & 1 & 1 & 1 & 1 & 2 & 1 \\
\hline Serious & 2 & 2 & 2 (tied) & 2 & 1 & 2 \\
\hline Credible & 3 & 3 & 2 (tied) & 3 & 3 & 3 \\
\hline Pushy & 4 & 4 & 4 & 4 & 5 & 4 \\
\hline Nosey & 5 & 5 & 5 (tied) & 5 & 4 & 5 \\
\hline Conservative & 6 & 6 & 5 (tied) & 6 & 7 & 6 \\
\hline Fun & 7 & 7 (tied) & 7 & 8 & 6 & 8 \\
\hline Good looking & 8 & 7 (tied) & 8 & 7 & 7 (tied) & 7 \\
\hline
\end{tabular}

Rankings of selected qualities of male journalists by secondary school students in Christchurch and Australia.

Again, the first observation is that the rankings are remarkably similar across both the national groups and the genders, with the only national total variation being between the very bottom ranked qualities of male journalists as 'fun' and 'good looking'. Clearly, 'intelligent', 'serious' and 'credible' are ranked in the top three by all genders across both national groups, with only Australian males disagreeing on the top two rankings. Male journalists' perceived pushiness or nosiness are ranked clearly in the middle and their conservative nature, 'fun' and good looks are all at the bottom of the league table. There does not seem to be enough variation within the male/female or Australia/NZ samples worthy of further elucidation.

\section{Perceptions of female journalists}

It is when the secondary school students' perceptions of female journalists across the two countries are factored into the equation that we start to see some significant differences, worthy of further discussion and inquiry. Table 5 details the shifts, with the most notable for the New Zealand cohort being the elevation of 'good looking' as a quality of journalists from last for the male journalists up to fourth for the females.

At first glance it appears this is the major variation from Table 4, with the other rankings remaining relatively constant apart from a shift of a single place or two. 


Table 5: Rankings of selected qualities of female journalists
\begin{tabular}{|l|c|c|c|c|c|c|}
\hline $\begin{array}{l}\text { Ranking of } \\
\text { qualities of } \\
\text { female journalists }\end{array}$ & \multicolumn{3}{|c|}{$\begin{array}{c}\text { New Zeand (n=160 } \\
\text { students) }\end{array}$} & \multicolumn{3}{c|}{ Australia (n=444 students) } \\
\hline & All & $\begin{array}{c}\text { Male } \\
(\mathrm{n}=73)\end{array}$ & $\begin{array}{c}\text { Female } \\
(\mathrm{n}=87)\end{array}$ & All & $\begin{array}{c}\text { Male } \\
(\mathrm{n}=182)\end{array}$ & $\begin{array}{c}\text { Female } \\
\text { (n=262) }\end{array}$ \\
\hline Intelligent & 1 & 1 & 1 & 1 & 5 & 1 \\
\hline Credible & 2 & 3 & 2 & 6 & 6 & 3 \\
\hline Serious & 3 & 2 & 3 & 2 & 4 & 2 \\
\hline Good looking & 4 & 5 & 4 & 3 & 1 & 5 \\
\hline Nosey & 5 & 4 & 6 & 5 & 3 & 6 \\
\hline Pushy & 6 & $6($ tied) & 5 & 4 & 2 & 4 \\
\hline Fun & 7 & $6($ tied) & 6 & 8 & 8 & 8 \\
\hline Conservative & 8 & 8 & 8 & 7 & 7 & 7 \\
\hline
\end{tabular}

Rankings of selected qualities of female journalists by secondary school students in Christchurch and Australia.

However, the Australian students' rankings tell a markedly different story, both compared with the New Zealanders and across their own gender divisions. Australian teenagers overall have elevated 'good looking' as a female journalist quality to third ranking compared with seventh for male journalists but, more notably, male students have promoted good looks to their number one ranked quality of female journalists. Girls, on the other hand, disagree, and have only promoted good looks from seventh to fifth over male journalists' qualities.

Following through with the Australian boys' impressions of female journalists' qualities starts to sound alarming. Their top three nominated ranked qualities are 'good looking', 'nosey' and 'pushy', offering a disturbingly uncomplimentary view of Australian women working in the career.

This contrasts markedly with the top three qualities nominated by the high school girls: 'intelligent', 'serious' and 'credible' — exactly the same qualities and order they assigned to male journalists.

Is this just the hormonal reaction of pubescent Australian boys or does it say something important about the female faces they see on Australian television news and the appearance of their female classmates who are aiming for a career in journalism? Could they be influenced by the prime-time tabloid television current affairs programmes with their female anchors and reporters displaying such characteristics on a nightly basis? Could they also be 
influenced by the parodies of these individuals which have made for popular viewing in satirical programmes like the Australian Broadcasting Corporation's The Chaser and on the internet file-sharing site YouTube.

It is certainly a marked difference from the New Zealand findings, although Densem's (2006) study found the female good looks accompanied by a lack of being taken seriously as a quality emanating from her deeper focus group interviews. This dynamic is certainly worthy of further pursuit and our own interviews with careers advisers and elite journalists might shed further light on it, although it is likely to need a targeted study testing this tabloid television hypothesis.

\section{Conclusion}

Where does all this lead us in our examination of the feminisation of journalism as a career and its overwhelming comparative popularity among young women compared with young men in both countries?

It tells us that secondary school students on both sides of the Tasman share many similar perceptions of journalism as a career and the males and females practising that career, but also some noteworthy differences.

More than half of high school students in both countries claim to access the news daily, with television the most popular medium of choice. Australian teenagers seemed to have a higher internet access habit for their news, although this could be attributable to the three years between the studies.

High school students in both countries see journalism as more 'interesting' and 'difficult' than 'fun', and all seemed aware of the feminisation of the occupation over recent years because an overwhelming majority from both countries and across both genders rejected the description of the career as 'blokey'.

All displayed substantial ignorance about journalists' incomes, so there did not seem to be a perception among males that it was a well paid career. This might offer a hint as to why many young men are choosing not to pursue it.

Another indicator could be the level of respect of journalism as a career, with fewer males than females perceiving it as a 'well respected career', and only 29 percent of Australian boys seeing it that way.

However, the key clues to their selection or non-selection of journalism as a career might lie in their perception of working journalists in each country. Almost all of the high school students perceive both male and female journalists as 'intelligent', 'serious' and 'credible' in both countries. If the 
self-perception of teenage boys differs from this we might well have cracked the nut of the issue of the career's relative lack of popularity among young men. Factor in the Australian boys' perception of female journalists as good looking, pushy and nosey and we might well have a reason why they might feel intimidated by the prospect of such a workplace. We are looking forward to reviewing the results of the other elements of our study, examining careers advisers' and elite journalists' perspectives on the issue before we draw any firmer conclusions on the matter. As part of that inquiry we might also need to revisit the high school students, or at least the literature on the self-image of teenage boys.

Either way, there appears to be considerable work ahead of journalism educators in both countries if they are to correct some of the misconceptions about the career in the minds of the general secondary school population. It appears prime time television news and current affairs is a strong influence on teenagers' understanding of journalism as a career when the reality is that most journalists work in other sections of the industry. We will also need to examine high school curricula, particularly in the media studies area, to see whether the image of journalism as a career being portrayed reflects the reality of the occupation we know.

\section{References}

Alysen, B., \& Oakham, M. (1996). The Jana Wendt factor: an empirical study of myths and misconceptions among journalism students. Australian Journalism Review, 18(1), 39-52.

Becker, L. B., Vlad, T., Vogel, M., Wilcox, D., \& Hanisak, S. (2008). Enrolments increase, with slightly higher percentages of male students. Journalism and Mass Communication Educator, 63(3), 198-223.

Day, E. (2004). Why women love journalism. British Journalism Review, 15 (2): 21-25.

Densem, Y. (2006). Where have all the young men gone? Gender imbalance in tertiary journalism courses. Pacific Journalism Review, 12(1), 37-53.

Djerf-Pierre, M. (2007) The gender of journalism. The structure and logic of the field in the twentieth century. Nordicom Review, Jubilee Issue. pp. 81-104. Online. Retrieved on 22 September 2009, from www.nordicom.gu.se/common/ publ_pdf/248_248_djerf-pierre1.pdf

Economist, The (2005). The fame machine. 376(8442), 49.

Endres, F. F., \& Weardon, S. T. (1990). Career choices, perceptions of work by undergrads. Journalism Educator, 45(1), 28-35.

Fitzsimmons, P., \& Bilboe, W. (1999). Is it the 'write' way? [Electronic Version]. 
The Australian Association for Research in Education. Retrieved on 1 September 2008, from www.aare.edu.au/99pap/fit99136.htm.

Fisher, H. A. (1978). Broadcast journalists' perceptions of appropriate career preparation. Journalism Quarterly, 55(1), 140-144.

Frith, S., \& Meech, P. (2007). Becoming a journalist: journalism education and journalism culture. Journalism, 8(2), 137-164.

Hanna, M., \& Sanders, K. (2007). Journalism education in Britain: who are the students and what do they want? Journalism Practice, 1(3), 404-420.

Henningham, J. (1996). Australian Journalists' professional and ethical values. Journalism \& Mass Communication Quarterly, 73(1), 206-218.

Hollings, J., Lealand, G., Samson, A., \& Tilley, E. (2007). The big NZ journalism survey: underpaid, under-trained, under-resourced, unsure about the future-but still idealistic. Pacific Journalism Review, 13(2), 175-197.

North, L. (2009). The gendered newsroom. Cresskill, New Jersey: Hampton Press.

Patching, R. (1997). Too many students, not enough jobs?: A comparative study of Australian journalism programs. Unpublished MA (Hons) thesis, University of Wollongong, Wollongong.

Pearson, M. (1988). 'I want to be a journalist': A study of cadetships. Australian Journalism Review, 10: 125-134.

Peters, B. (2001, June). Equality and quality: setting standards for women in journalism. IFJ survey on the status of women journalists. Brussels: IFJ. Online. Retrieved on 22 September 2009, from www.ifj.org/assets/docs/231/007/a61e5e7-2c52b07. pdf

Robinson, G. J. (2008). Feminist approaches to journalism studies: Canadian perspectives. Global Media Journal —Canadian Edition. 1 (1), 123-136. Retrieved on 22 September 2009, from www.gmj.uottawa.ca/inaugural_robinson.pdf

Splichal, S., \& Sparks, C. (1994). Journalists for the 21st century: Tendencies of professionalisation among first-year students in 22 countries. Norwood, New Jersey: Ablex Publishing.

Professor Mark Pearson is head of journalism and director of the Centre for New Media Research and Education at Bond University, Queensland, Australia. He thanks Yvonne Densem, formerly of the New Zealand Broadcasting School, for making available the survey data upon which the comparison is based; doctoral candidates Jill Borchard and Naomi Busst for their research assistance; and the Faculty of Humanities and Social Sciences at Bond University for its research funding for the project. An earlier version of this paper was presented at the annual conference of the Journalism Education Association of New Zealand, Christchurch, December 8-9, 2008. The author thanks the reviewers for their useful feedback. mpearson@bond.edu.au 